index comunicación | no 10(1) 2020 | Páginas 173-194

E-ISSN: 2174-1859 | ISSN: 2444-3239 | Depósito Legal: M-19965-2015

Recibido el 30_05_2020 | Aceptado el 18_06_2020 | Publicado el 15_10_2020

\title{
ATRIBUTOS DE LIDERAZGO EN INSTAGRAM DURANTE LAS ELECCIONES PRESIDENCIALES EN ARGENTINA 2019
}

\author{
LEADERSHIP ATTRIBUTES ON INSTAGRAM \\ DURING THE PRESIDENTIAL ELECTIONS \\ IN ARGENTINA 2019
}

https://doi.org/10.33732/ixc/10/01Atribu

\author{
Virginia García Beaudoux \\ CONICET-IIGG-Universidad de Buenos Aires \\ copub@ub.edu.ar \\ https://orcid.org/0000-0003-2428-8056 \\ Salomé Berrocal-Gonzalo \\ Universidad de Valladolid (España) \\ salomeb@hmca.uva.es \\ http://orcid.org/0000-0002-0483-0509
}

\section{Orlando D'Adamo} Universidad de Buenos Aires (Argentina) dagar02@gmail.com https://orcid.org/0000-0003-4871-6633

Este artículo forma parte del proyecto de investigación CSO2017-84472-R: Politainment en el entorno de la posverdad: nuevas narrativas, clickbait y gamificación (POLITGAMENT), financiado por el Ministerio de Economía y Competitividad. 
174

Resumen: La investigación analiza los contenidos que 32 candidatos y candidatas publicaron en sus cuentas de Instagram durante el mes previo a la fecha de las elecciones presidenciales en Argentina de 2019. Se utilizó el método de análisis de contenido, con el objetivo de evaluar dos variables: tipo de información publicada, y estilo de liderazgo comunicado. Los principales resultados indican que privilegiaron el contenido propiamente político más que el politainment, y la proyección de habilidades duras de liderazgo más que blandas. Por su parte, los usuarios de Instagram manifiestan su preferencia por las publicaciones en las que se comunican habilidades blandas de liderazgo, sobre todo cuando se trata de las publicaciones de las candidatas.

Palabras clave: Instagram; politainment; liderazgo; género; comunicación política; prosumidores.

Abstract: The research analyzes the content that 32 male and female candidates published on their Instagram accounts during the month prior to the date of the 2019 presidential elections in Argentina. The content analysis method was used, in order to evaluate two variables: type of published information and communicated leadership style. The main results indicate that they privileged the strictly political content more than politainment, and the projection of hard leadership skills more than soft ones. For their part, Instagram users express their preference for posts in which soft leadership skills are communicated, especially when it comes to the posts of the female candidates.

Keywords: Instagram; Politainment; Leadership; Gender; Political Communication; Prosumers. 


\section{Instagram, politainment e imágenes de liderazgo}

Este trabajo presenta los resultados de una investigación en la que se analiza el uso que varones y mujeres que presentaron candidaturas hicieron de la red social Instagram durante la campaña electoral de las elecciones de octubre de 2019 en Argentina. Los objetivos planteados son cuatro: el primero, explora las características de la información atendiendo a la proporción de politainment o de información propiamente política en las publicaciones que efectuaron; el segundo, estudia la frecuencia de atributos de liderazgo duros y blandos comunicados; el tercero, analiza si existen diferencias en la comunicación de atributos hard y soft de liderazgo según el género de quien se postula a una candidatura; el cuarto, explora las características en términos de contenido informativo versus politainment y de atributos de liderazgo blandos versus duros $\mathrm{y}$, además, establece las publicaciones que recibieron más likes por parte de los usuarios.

En la actualidad, el 49\% de la población del mundo utiliza redes sociales e Instagram es una red en expansión (WeAreSocial, 2020). A finales de 2017, dicha plataforma contaba con más de 800 millones de seguidores y se producían aproximadamente 300 millones de publicaciones diarias (Instagram, 2017; WeAreSocial, 2018). En 2018, el 76\% de la población argentina ya se encontraba activa en redes sociales y de las ocho horas diarias que dedicaba a navegar por Internet, más de tres de ellas se destinaban a las redes sociales, siendo Instagram la que conseguía mayor crecimiento (WeAreSocial, 2018). En 2020, Facebook era la red social que continuaba liderando el panorama de las redes sociales, con 2.449 millones de usuarios en el mundo, un 7,8\% más que en 2019. Instagram le seguía, posicionada en el segundo lugar, con 1.000 millones, 200 millones de usuarios más de los que tenía en 2019 (WeAreSocial, 2020).

Instagram es una plataforma que se ha adoptado para la producción y distribución de mensajes políticos, cifrados principalmente en códigos de imágenes de foto y video. Desde el punto de vista cognitivo, las imágenes son mucho más fáciles de procesar, comprender y recordar para la mente humana que las estadísticas, las ideas abstractas o los textos complejos; a lo que se suma su poder para de despertar las emociones. Las personas videntes confiamos en el sentido de la vista más que en cualquiera de los otros: ver otorga credibilidad. Frases del lenguaje popular como ver para creer, boyando en la oscuridad o lo vi con mis propios ojos, indican la capacidad inequívoca de revelar la verdad que atribuimos a lo visual (García Beaudoux, D’Adamo y Slavinsky, 2005). Los resultados de diversas investigaciones indican que nuestra habilidad para almacenar imágenes en la memoria, en comparación con otro tipo de datos, es extrema- 
damente alta (Vogt y Magnussen, 2007; Brady et al., 2008). Instagram es la primera aplicación de redes sociales diseñada específicamente para compartir fotografías y la que cuenta con mayor popularidad y aprobación (Quevedo Redondo y Portalés Oliva, 2017). Si bien su uso se ha profesionalizado, su naturaleza visual y móvil genera en la ciudadanía la ilusión de una comunicación política más espontánea, que combina vida pública y privada, caracterizada por una mezcla de deliberada puesta en escena y autenticidad (Selva y Caro, 2017). López y Domenéch (2018) indican que la profesionalización del uso de la imagen política en las redes sociales responde, entre otros factores, a que facilita a los candidatos a presentarse de manera efectiva mezclando elementos de su vida personal y profesional, y a que las imágenes son herramientas poderosas para capturar la atención y persuadir. En ese sentido, Instagram permite comunicar contenidos que alimentan en los usuarios receptores la sensación de intimidad y cercanía respecto de los emisores, como así también contenidos que incluyen gran carga espectacular en el mensaje político (Montagut y Carrillo, 2017; López García 2017). En el terreno de las organizaciones, se argumenta que la marca es uno de sus activos intangibles más importantes porque la percepción que los consumidores tengan de ella se ve reflejada en los resultados económicos (Ruiz-Aguilar y Avalos-Pelayo, 2020). En la arena política, la marca personal resulta un elemento a considerar a la hora de presentar candidaturas para la competencia electoral, ya que la percepción que los votantes se formen es dable esperar que afectará los resultados electorales. Instagram es una ventana que permite reflejar un estilo personal y unos valores de marca a quienes presentan candidaturas electorales.

El afán de fidelizar, conseguir nuevas audiencias y movilizar seguidores, hace que los partidos políticos y sus candidatos tiendan con frecuencia a optar por un estilo de comunicación política personalizada, que incluye aspectos de la vida privada y que recurre a conocidas tácticas como la visualización, la simplificación y la polarización (Meyen, Thieroff y Strenger, 2014). En Instagram, en particular, se publican mensajes simples en forma de fotos, álbumes, selfies, videos y collages, que persiguen la conexión emocional con la ciudadanía, humanizando a líderes y candidatos protagonistas en autopresentaciones en las que se destacan sus atributos personales y sus competencias, en mensajes naturales, cercanos y espontáneos que generan ilusión de intimidad (Ekman y Widholm, 2017). Aun cuando el uso de Instagram en la arena política se encuentra en una fase experimental e inicial o, en el mejor de los casos intermedia, se la considera una plataforma con capacidad de mejorar el intercambio con los votantes, movilizarlos, recaudar fondos, instalar ciertas agendas y tendencias, así como de potenciar la construcción de liderazgo a través de la 
personalización de los líderes (Towner y Muñoz, 2017). De ahí la importancia de estudiarla en el contexto de una campaña electoral.

Si bien a lo largo de la historia las imágenes proyectadas por los políticos han sido centrales para las evaluaciones y conceptos que los votantes mantienen de quienes presentan candidaturas (García Beaudoux, D'Adamo y Slavinsky; 2005), la televisión y la web 2.0 le otorgan una importancia aún mayor a la imagen digital personalizada y al uso estratégico que candidatos y partidos políticos hacen de ella para conectar de modo directo con la ciudadanía (López y Doménech, 2018). Instagram establece un espacio visual de la política en la que se mezcla lo informativo y lo personal, los contenidos propiamente políticos con el entretenimiento, con un estilo que permite inclusive la espectacularización (Quevedo y Portalés, 2017). Por esa razón, ofrece una nueva plataforma al politainment y a la celebrificación de la política entendida como la producción de mensajes y un contenido ameno, junto con la humanización de las acciones de gobierno con la finalidad principal de aumentar la atención y disminuir la apatía de los votantes (West y Orman, 2002; Wheeler, 2013; Richardson, 2015).

El politainment comenzó a ser tenido en cuenta a inicios de los años 1990 (Patterson, 2000; Hamilton, 2004; Berrocal, 2015). Las campañas incorporan con frecuencia este tipo de comunicación que se caracteriza por presentar más contenido de entretenimiento que informativo. Estudios realizados por diversos investigadores (Baum, 2002, 2005 y 2007; Berrocal et al. 2001 y 2003; Brants, 1998) señalan que el fenómeno se repite en la mayoría de las democracias occidentales y que el politainment se ha transformado en un sustituto frecuente de la información política propiamente dicha al incorporar dramatismo, historias, sentimientos e ingredientes de humor. Las primeras investigaciones sobre el fenómeno se limitaron a un medio de comunicación: la televisión. Con posterioridad, comenzó a ser investigado en Internet, específicamente en plataformas como YouTube, Facebook y Twitter (Tyron, 2008; Towner y Dulio, 2011). En la actualidad, continúa siendo una línea de trabajo en la que no existe un gran corpus de producción académica. Los estudios que analizan el politainment o infoentretenimiento político en Internet, en su mayoría, se han centrado en la red social YouTube (Tyron, 2008; Towner y Dulio, 2011). Facebook, Twitter e Instagram aún no cuentan con estudios sistemáticos.

En tanto plataforma visual y dada su tasa de crecimiento, Instagram abre una nueva posibilidad para continuar explorando la clase de información que se comunica durante las campañas electorales, y la proporción en ellas de información propiamente política y de politainment. Los indicadores para la medición de ambas categorías han sido establecidos en este trabajo en torno a 
la detección de noticias duras (información pura) y noticias blandas (politainment) tal y como fueron conceptualizadas por Reinemann y colaboradores, quienes estipulan que

[...] cuanto más un ítem noticioso sea políticamente relevante, cuanto más se reporte de un modo temático, se enfoque en las consecuencias sociales de los eventos, sea impersonal y no emocional en su estilo, más podrá ser considerado como noticia dura [...] cuanto más un ítem noticioso no sea políticamente relevante, cuanto más sea reportado de un modo episódico, se enfoque en las consecuencias individuales de los eventos, sea personal y emocional en su estilo, más podrá ser considerado noticia blanda (Reinemann et al., 2011: 13).

Instagram abre nuevos interrogantes no solo para la exploración del tipo de información predominante comunicada, sino también para la exploración de este fenómeno: ¿qué atributos de liderazgo son los que las y los candidatos con más frecuencia proyectan e intentan reforzar mediante los videos, imágenes y publicaciones que realizan en sus cuentas de Instagram?, ¿los denominados atributos duros de perfil técnico, o atributos blandos tales como empatía y habilidades interpersonales, que resultarían más sintónicos con el espíritu del politainment?

En las páginas que siguen se discuten los resultados obtenidos en una investigación que realizamos con la finalidad de explorar ambas variables: por una parte, qué tipo de información se comunica en Instagram durante una campaña electoral; y por otra, qué atributos de liderazgo predominan en los contenidos que quienes postulan candidaturas comunican desde sus cuentas en Instagram en esos períodos electorales.

\section{Método y muestra}

El estudio empírico realizado es de carácter exploratorio, alcance descriptivo y de secuencia temporal transversal. Se utiliza el método de análisis de contenido cuantitativo, que produce datos nominales o frecuencias que cuentan la ocurrencia de determinado tipo de contenido (Krippendorff, 1990; Neuendorf, 2002; Igartua, 2006), por ser el que mejor se ajusta al objeto de estudio seleccionado. La selección de las variables y el establecimiento de los indicadores de las variables incluidas en el diseño de la investigación se deriva de una extensiva revisión bibliográfica, y de categorías creadas y utilizadas por los autores en investigaciones similares anteriores (García Beaudoux y D’Adamo, 2017, 2016, 2016a, 2016b y 2013; García Beaudoux, D’Adamo y Zubieta, 2016; D'Adamo, García Beaudoux y Kievsky, 2015) que asimismo han sido citadas y utilizadas por otros investigadores (Quevedo Redondo y Portalés Oliva, 2017; López y Doménech, 2018). Con la finalidad de aumentar la con- 
fiabilidad, se utilizaron categorías excluyentes y descriptivas que requirieran bajo nivel de inferencia por parte de los codificadores.

La muestra está conformada por un total de 1505 unidades. Las unidades de análisis son las publicaciones de Instagram efectuadas por los 32 candidatos que obtuvieron la mayor cantidad de votos en las PASO (elecciones Primarias Abiertas y Obligatorias) en los tres distritos electorales más grandes de Argentina (Provincia de Buenos Aires, Provincia de Córdoba y Provincia de Santa Fe). Eso los habilitó para competir por cargos de elección popular para la presidencia de la nación, gobernaciones provinciales y cargos legislativos para el Congreso Nacional. Las elecciones que tuvieron lugar en Argentina en octubre de 2019. Se analizan todas las publicaciones que realizaron (fotografías, videos, álbumes y sus respectivos textos) en sus feeds de Instagram, en el período comprendido durante los 30 días previos a la fecha en que tuvieron lugar las elecciones (tabla 1).

Tabla 1. Características de muestra y de las unidades de análisis

\begin{tabular}{|l|r|r|}
\hline $\begin{array}{c}\text { Tipo de unidad } \\
\text { de análisis }\end{array}$ & $\begin{array}{c}\text { N total de unidades } \\
\text { de análisis = 1505 }\end{array}$ & \multicolumn{1}{c|}{$\%$} \\
\hline Foto / imagen & 544 & $36 \%$ \\
\hline Video & 391 & $26 \%$ \\
\hline Álbum & 570 & $38 \%$ \\
\hline Total & 1.505 & $100 \%$ \\
\hline
\end{tabular}

Fuente: elaboración propia.

Las publicaciones que conforman la muestra corresponden a las y los candidatos de los tres distritos electorales más grandes de Argentina a los siguientes cargos ejecutivos y legislativos: presidencia de la nación (cargo ejecutivo nacional), vicepresidencia de la nación, gobernación provincial (cargo ejecutivo provincial), vicegobernación provincial y candidaturas del primer y segundo lugar de cada una de las tres listas más votadas para congresistas nacionales (cargo legislativo nacional) en cada uno de los tres distritos. En las tablas 2, 3 y 4 se observa el detalle de las candidaturas seleccionadas para el análisis de sus publicaciones en Instagram.

Tabla 2. Candidaturas por género

\begin{tabular}{|l|r|r|}
\hline \multicolumn{1}{|c|}{$\mathbf{N ~ 3 2}$} & $\mathbf{N}$ & $\%$ \\
\hline Candidatas & 1 & $37,5 \%$ \\
\hline Candidatos & 20 & $62,5 \%$ \\
\hline Total & 32 & $100 \%$ \\
\hline
\end{tabular}

Fuente: elaboración propia. 
Tabla 3. Tipo y género de las candidaturas

\begin{tabular}{|l|r|r|r|}
\cline { 2 - 4 } \multicolumn{1}{c|}{} & \multicolumn{2}{c|}{$\begin{array}{c}\text { Presidencia } \\
\text { de la Nación }\end{array}$} & \multicolumn{2}{c|}{$\begin{array}{c}\text { Vicepresidencia } \\
\text { de la Nación }\end{array}$} & $\begin{array}{c}\text { Gobernación } \\
\text { provincial }\end{array}$ \\
\hline Mujer & - & 1 & 1 \\
\hline Varón & 3 & $100 \%$ & $11,1 \%$ \\
\hline Total & $100 \%$ & - & 8 \\
& $100 \%$ & 1 & $88,8 \%$ \\
\hline
\end{tabular}

\begin{tabular}{|l|r|r|r|}
\hline & $\begin{array}{l}\text { Vicegobernación } \\
\text { provincial }\end{array}$ & $\begin{array}{c}\text { Congresista Nacional } \\
(10 \text { lugar en la lista) }\end{array}$ & $\begin{array}{c}\text { Congresista Nacional } \\
\left(\mathbf{2}^{\circ} \text { lugar en la lista }\right)\end{array}$ \\
\hline Mujer & 1 & 1 & 8 \\
Varón & $100 \%$ & $11,1 \%$ & $88,8 \%$ \\
\hline Total & -8 & $88,8 \%$ & 1 \\
& $100 \%$ & 9 & $11,1 \%$ \\
\hline
\end{tabular}

Fuente: elaboración propia. 
Tabla 4. Muestra de candidatos y candidatas en Instagram

\begin{tabular}{|c|c|c|c|c|c|c|c|c|c|c|c|c|c|c|c|}
\hline 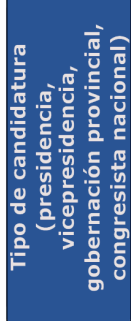 & 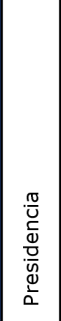 & 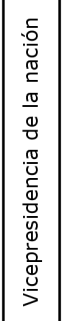 & 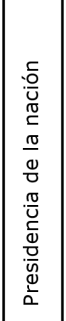 & 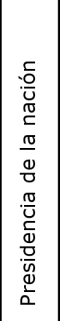 & 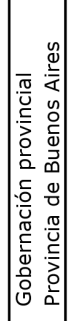 & 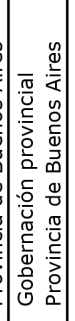 & 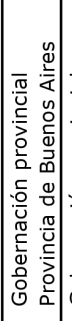 & 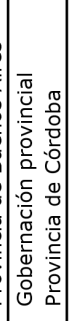 & 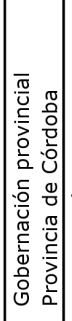 & 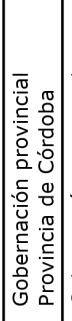 & 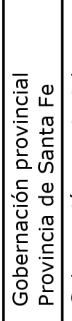 & 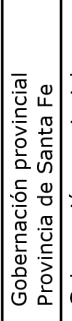 & 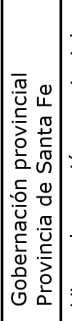 & 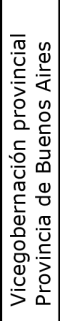 & 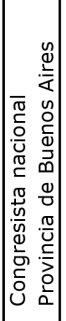 \\
\hline 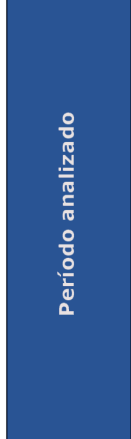 & 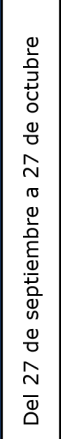 & 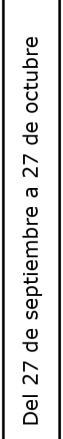 & 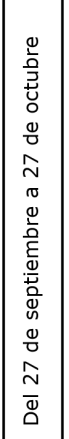 & 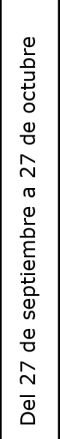 & 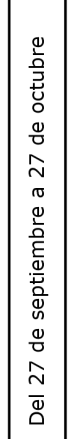 & 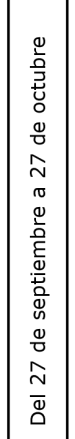 & 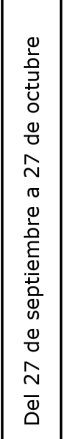 & 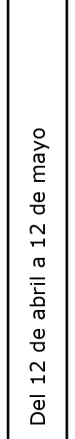 & 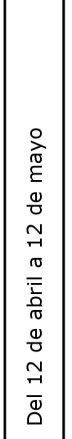 & 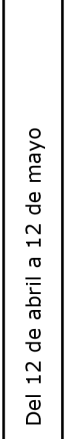 & 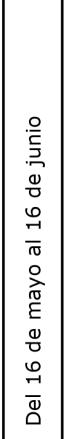 & 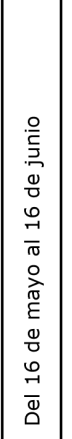 & 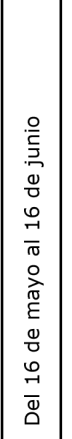 & 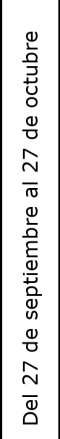 & 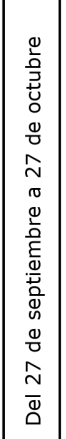 \\
\hline 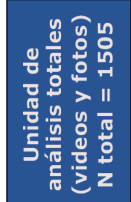 & ה & $\vec{N}$ & in & $\stackrel{2}{N}$ & $\mathcal{F}$ & $\AA$ & in & $\stackrel{M}{\wedge}$ & f & $\sigma$ & $\stackrel{-1}{0}$ & $\%$ & ৪ & $\vec{\Lambda}$ & $\grave{N}$ \\
\hline 尊 & \begin{tabular}{|l|} 
\\
$J$ \\
-
\end{tabular} & \begin{tabular}{|l|}
$\Sigma$ \\
\\
-
\end{tabular} & \begin{tabular}{|l|} 
\\
$N$ \\
$T$
\end{tabular} & \begin{tabular}{|c|}
$\underline{y}$ \\
no \\
o- \\
\end{tabular} & \begin{tabular}{l|l}
\multirow{2}{*}{} \\
$\mathbb{0}$ \\
\end{tabular} & $\begin{array}{l}\stackrel{y}{r} \\
\vec{M} \\
\infty\end{array}$ & $\begin{array}{l}\stackrel{x}{\wedge} \\
\end{array}$ & $\begin{array}{l}\stackrel{y}{\wedge} \\
\hat{m} \\
m\end{array}$ & 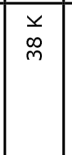 & $\begin{array}{l}\stackrel{y}{n} \\
\text { nn } \\
\text { my }\end{array}$ & 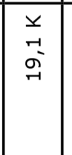 & $\begin{array}{l}\stackrel{\searrow}{N} \\
\stackrel{-}{N}\end{array}$ & 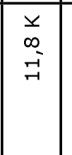 & $\begin{array}{l}\overline{\bar{E}} \\
+ \\
\vec{\nabla}\end{array}$ & $\begin{array}{l}\geq \\
-1 \\
\dot{\sigma} \\
\dot{\sigma}\end{array}$ \\
\hline 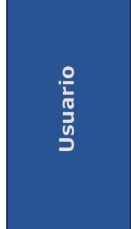 & 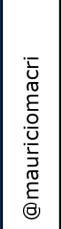 & 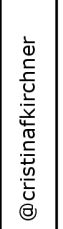 & 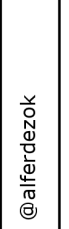 & 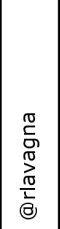 & 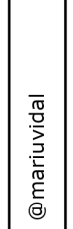 & 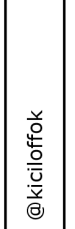 & 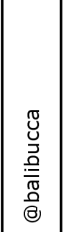 & 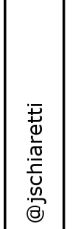 & 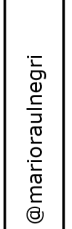 & 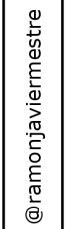 & 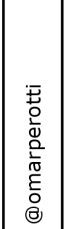 & 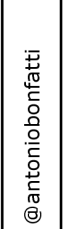 & 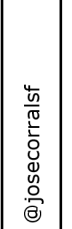 & 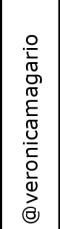 & 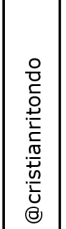 \\
\hline 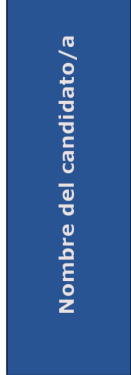 & 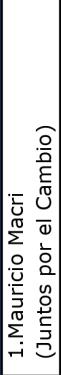 & 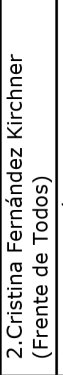 & 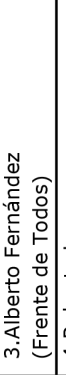 & 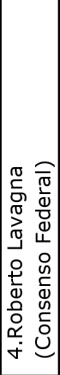 & 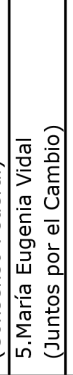 & 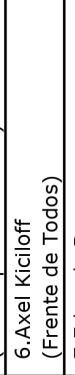 & 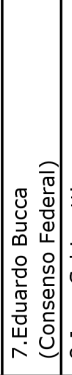 & 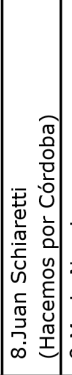 & 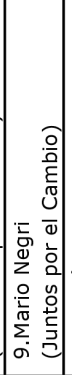 & 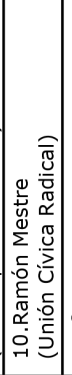 & 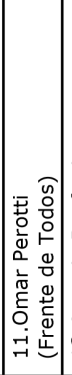 & 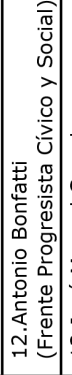 & 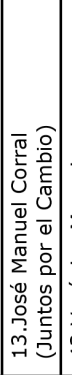 & 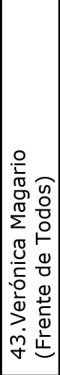 & 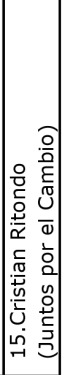 \\
\hline
\end{tabular}




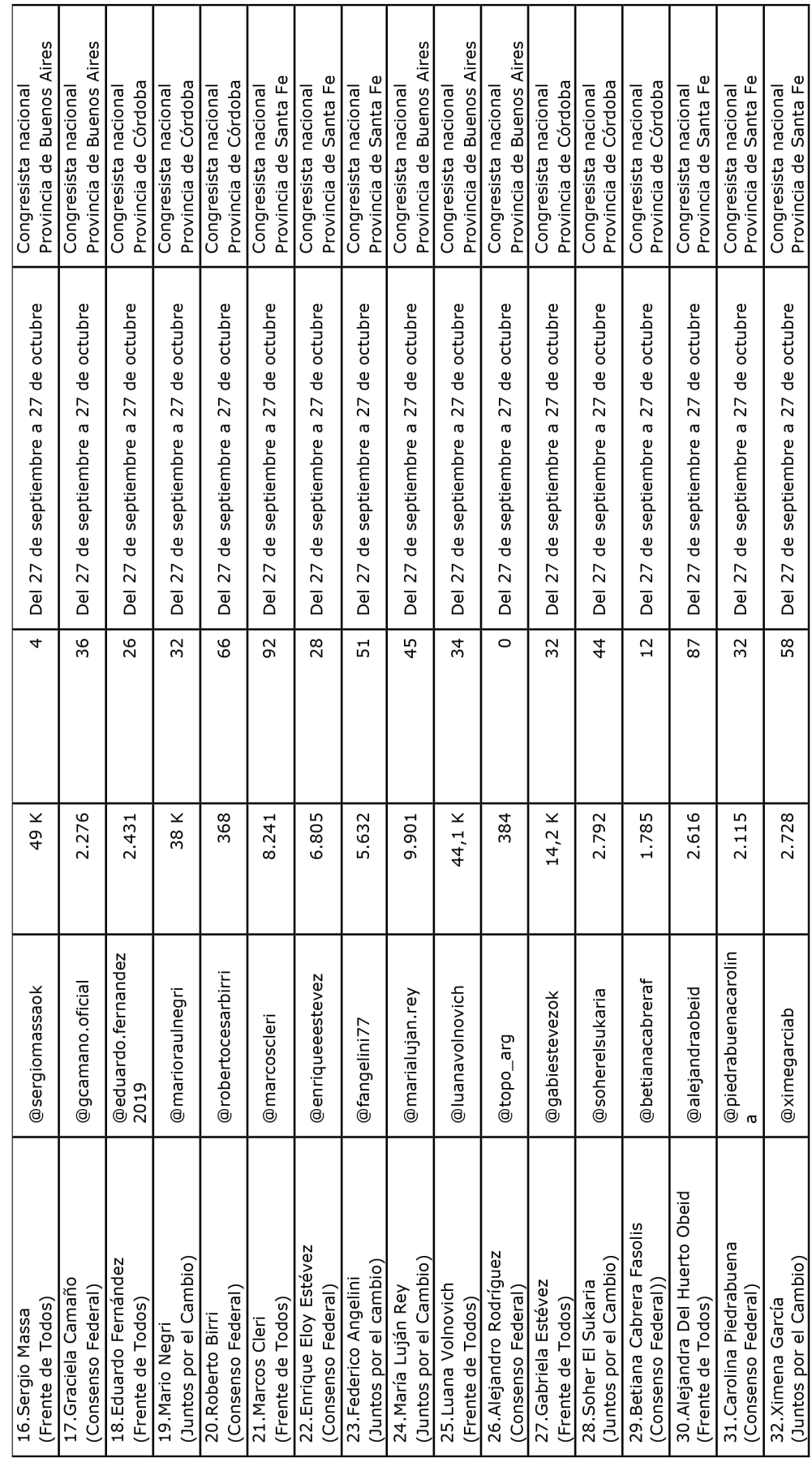

Fuente: elaboración propia. 
Para el registro y la medición de contenidos se diseñó un protocolo de codificación que fue sometido a una prueba piloto, en la que participaron los tres codificadores que efectuaron la medición definitiva. Con referencia a la fiabilidad del análisis, se siguió el modelo de Lemish y Tidhar (1999), una fórmula basada en el consenso entre los codificadores para elegir una única entrada o categoría para cada variable. En las situaciones en que los codificadores no alcanzaron un acuerdo, se siguió el procedimiento de Garramone, Steele y Pinkleton (1991) y el desacuerdo fue resuelto eligiendo la codificación seleccionada por dos de los tres.

En cuanto a las categorías y matriz de clasificación con los indicadores estipulados para cada variable, se presentan a continuación:

1. Variable 1: Tipo de información comunicada

1.1. Valor de la variable. Información propiamente política (noticias duras):

- Definición conceptual: publicaciones referidas a temas, eventos, normas, objetivos, intereses o actividades relacionados con la preparación, afirmación o implementación de decisiones políticas.

- Definición operacional: mención de actores sociales, de autoridades vinculadas con los procesos de toma de decisión, referencias a un plan o programa propuesto y/o a las personas preocupadas por esa decisión. El marco o frame utilizado hace énfasis en la relevancia y/o consecuencia pública de la información que se presenta.

1.2. Valor de la variable. Politainment (noticias blandas):

- Definición conceptual: infoentretenimiento político, predominio de contenido de entretenimiento sobre el informativo.

- Definición operacional: presencia de personas del ámbito político en espacios no específicamente políticos o informativos, presencia de información política blanda y entretenida en las publicaciones, tendencia a la personalización y a concentrar el protagonismo en los candidatos. El marco o frame utilizado hace énfasis en aspectos privados o personales. Se prioriza el contenido anecdótico, emotivo y humano sobre los contenidos políticos, cívicos o públicos.

2. Variable 2: Habilidades de liderazgo comunicadas

2.1. Valor de la variable. Habilidades duras.

- Definición conceptual: estilo de liderazgo centrado en las competencias y habilidades técnicas y estratégicas que muestra 
una o un candidato porque entiende que se requieren para ocupar el cargo que se pretende.

- Definición operacional: ejecutividad, capacidad de dirección, administración y planificación estratégica.

2.2. Valor de la variable. Habilidades blandas.

- Definición conceptual: estilo de liderazgo centrado en destrezas de comunicación, técnicas interpersonales y sociales, inteligencia emocional y habilidades para la cooperación y el trabajo en equipo que muestra una candidata o un candidato para ocupar el cargo que se pretende.

- Definición operacional: comunicar entusiasmo, flexibilidad, habilidad para el trabajo en equipo, para interactuar con la ciudadanía, tendencia a la cooperación.

Las variables han sido convertidas en los siguientes indicadores que conforman la matriz que se ha utilizado para la clasificación de las unidades de análisis que componen la muestra (tabla 5).

Tabla 5. Matriz de clasificación

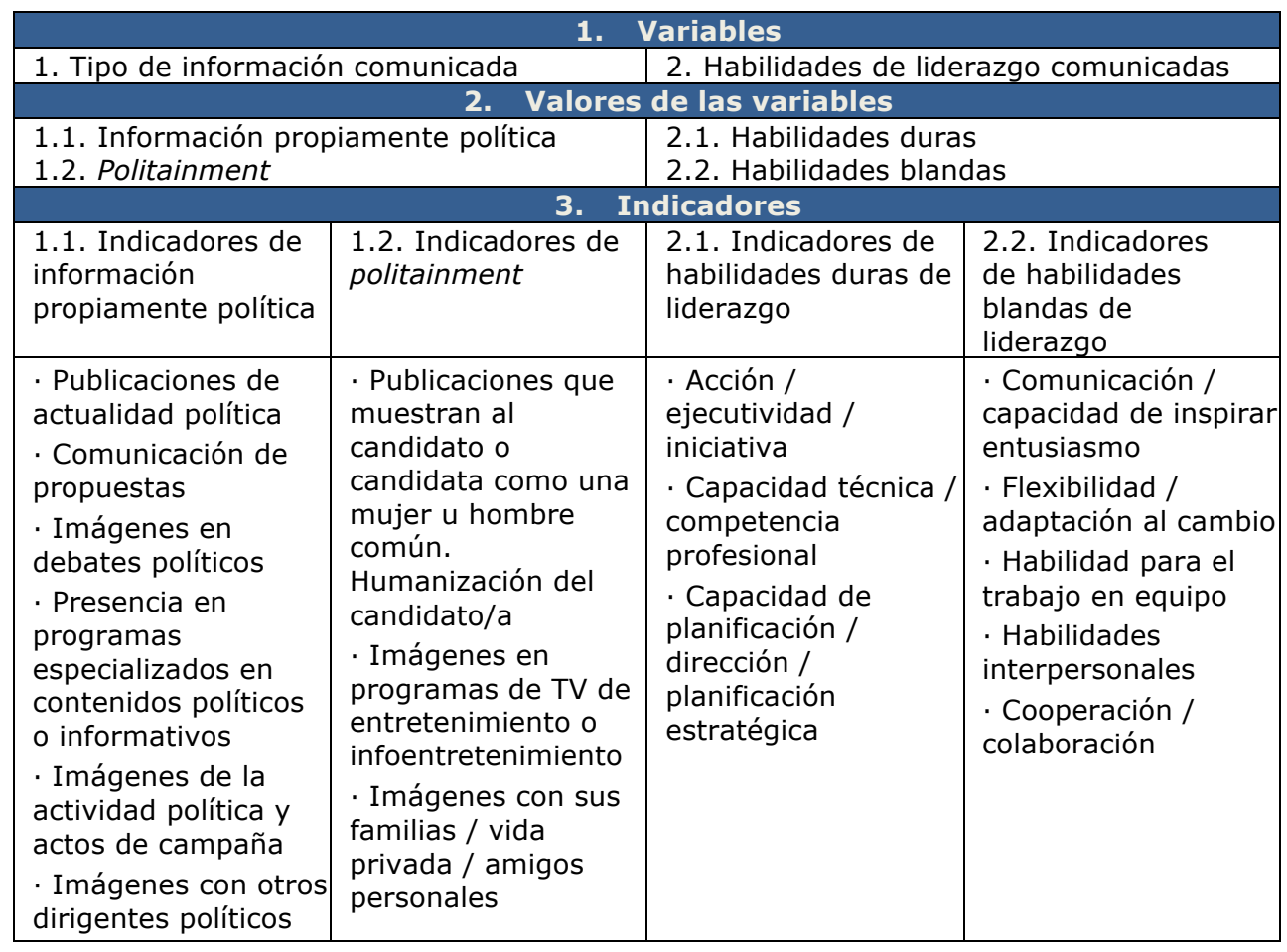




\begin{tabular}{|c|c|c|}
\hline $\begin{array}{l}\text { Petición de apoyo } \\
\text { y/o de voto } \\
\text { - Otras }\end{array}$ & $\begin{array}{l}\text { - Imágenes en } \\
\text { situaciones } \\
\text { informales con sus } \\
\text { equipos de trabajo } \\
\text { - Humor } \\
\text { - Otras }\end{array}$ & \\
\hline & Otras caracterí & cas de las publicaciones \\
\hline \multicolumn{2}{|c|}{ 1. Protagonismo de la imagen } & $\begin{array}{l}\text { Candidata/o } \\
\text { Otros dirigentes políticos } \\
\text { Ciudadanía } \\
\text { Medios de comunicación } \\
\text { Paisajes } \\
\text { Objetos } \\
\text { Familia / amigos } \\
\text { Colaboradores / equipo de trabajo } \\
\text { Otros }\end{array}$ \\
\hline \multicolumn{2}{|l|}{ 2. Escenario } & $\begin{array}{l}\text { Espacio político } \\
\text { Espacio privado } \\
\text { Espacio mediático } \\
\text { Espacio público }\end{array}$ \\
\hline \multicolumn{2}{|c|}{ 3. Vestimenta de candidatas y candidatos } & $\begin{array}{l}\text { Formal } \\
\text { Informal }\end{array}$ \\
\hline \multicolumn{2}{|c|}{ 4. Tipo de apelación dominante } & $\begin{array}{l}\text { Lógica } \\
\text { Emocional positiva } \\
\text { Emocional negativa } \\
\text { Mixta (lógica y emocional a partes iguales) }\end{array}$ \\
\hline
\end{tabular}

Fuente: elaboración propia.

\section{Resultados}

En este apartado se presentan los principales resultados obtenidos con relación a las variables seleccionadas. El primero de ellos es que, aun siendo Instagram un medio no diseñado originalmente para transmitir información propiamente política, ese fue el principal uso que le dieron los candidatos de ambos géneros tal y como se observa en la tabla 6 .

Tabla 6. Tipo de información política comunicada

\begin{tabular}{|l|r|r|}
\hline $\begin{array}{c}\text { Tipo de información } \\
\text { política comunicada }\end{array}$ & Información propiamente política & Politainment \\
\hline Resultados total muestra & $90,4 \%$ & $9,6 \%$ \\
\hline Resultados candidatas & $91,0 \%$ & $9,0 \%$ \\
\hline Resultados candidatos & $90,0 \%$ & $10 \%$ \\
\hline
\end{tabular}

Fuente: elaboración propia. 
En cuanto a la variable 'liderazgo', ha predominado la comunicación de las habilidades duras más tradicionales relacionadas con la política, tales como dirigir, tomar decisiones, planificar y elaborar programas. Sin embargo, llama la atención que la comunicación de habilidades blandas se acerca al $50 \%$ de las publicaciones efectuadas y, en el caso de las mujeres, lo supera (tabla 7).

Tabla 7. Habilidades de liderazgo comunicadas

\begin{tabular}{|l|r|r|}
\hline $\begin{array}{c}\text { Habilidades de liderazgo } \\
\text { comunicadas }\end{array}$ & $\begin{array}{c}\text { Habilidades duras } \\
\text { de liderazgo }\end{array}$ & $\begin{array}{c}\text { Habilidades blandas } \\
\text { de liderazgo }\end{array}$ \\
\hline Resultados total muestra & $52,0 \%$ & $48,0 \%$ \\
\hline Resultados candidatas & $49,0 \%$ & $51,0 \%$ \\
\hline Resultados candidatos & $53,4 \%$ & $46,6 \%$ \\
\hline
\end{tabular}

Fuente: elaboración propia.

Los usuarios de Instagram manifiestan su preferencia por las publicaciones en las que se comunican habilidades blandas de liderazgo, sobre todo en el caso de las candidatas. Con referencia a las habilidades duras se prefieren cuando son comunicadas por candidatos (tabla 8).

Tabla 8. Características del conjunto de las diez publicaciones de cada candidato que obtuvieron más likes

\begin{tabular}{|l|r|r|r|}
\hline $\begin{array}{l}\text { Las } 10 \text { publicaciones con más } \\
\text { likes de cada candidato/a }\end{array}$ & $\begin{array}{c}\text { Resultados } \\
\text { total muestra }\end{array}$ & $\begin{array}{c}\text { Resultados } \\
\text { candidatas }\end{array}$ & $\begin{array}{c}\text { Resultados } \\
\text { candidatos }\end{array}$ \\
\hline $\begin{array}{l}\text { Publicaciones con información } \\
\text { propiamente política }\end{array}$ & $83,5 \%$ & $84,3 \%$ & $82,9 \%$ \\
\hline Publicaciones con politainment & $16,5 \%$ & $15,7 \%$ & $17,1 \%$ \\
\hline $\begin{array}{l}\text { Comunicación de habilidades duras } \\
\text { de liderazgo }\end{array}$ & $47,4 \%$ & $45,0 \%$ & $48,9 \%$ \\
\hline $\begin{array}{l}\text { Comunicación de habilidades } \\
\text { blandas de liderazgo }\end{array}$ & $52,6 \%$ & $55,0 \%$ & $51,1 \%$ \\
\hline
\end{tabular}

Fuente: elaboración propia.

En cuanto a las características de aquellas publicaciones realizadas por candidatos de ambos géneros para comunicar información propiamente política, hay tres que destacan: actualidad política - categoría que concentra el $26,2 \%$ de las imágenes-; actividad política y actos de campaña - que concentra el 35,5\%—e imágenes de sí mismos con otros dirigentes políticos —que concentra un $16,3 \%$ - Si se atiende al género y al sumatorio de estas tres características, el $77,2 \%$ de las publicaciones corresponden a los candidatos y un $72 \%$ a las candidatas (tabla 9). 
Tabla 9. Características de las publicaciones de información propiamente política

\begin{tabular}{|l|r|r|r|}
\cline { 2 - 4 } \multicolumn{1}{c|}{} & $\begin{array}{c}\text { Resultados } \\
\text { total muestra }\end{array}$ & $\begin{array}{r}\text { Resultados } \\
\text { candidatas }\end{array}$ & $\begin{array}{r}\text { Resultados } \\
\text { candidatos }\end{array}$ \\
\hline Actualidad política & $26,2 \%$ & $26,1 \%$ & $26,3 \%$ \\
\hline Comunicación de propuestas & $9,5 \%$ & $9,6 \%$ & $9,4 \%$ \\
\hline Imágenes en debates políticos & $1,0 \%$ & $0,5 \%$ & \\
\hline $\begin{array}{l}\text { Imágenes participando en medios de } \\
\text { comunicación especializados en } \\
\text { contenidos políticos o informativos }\end{array}$ & $1,0 \%$ & $1,1 \%$ & $0,9 \%$ \\
\hline $\begin{array}{l}\text { Imágenes en actividad política y } \\
\text { actos de campaña }\end{array}$ & $35,5 \%$ & $32,6 \%$ & $36,9 \%$ \\
\hline $\begin{array}{l}\text { Imágenes de las y los candidatos con } \\
\text { otros dirigentes políticos }\end{array}$ & $16,3 \%$ & $18,5 \%$ & $15,3 \%$ \\
\hline Petición de apoyo y/o del voto & $9,4 \%$ & $10,0 \%$ & $9,0 \%$ \\
\hline Otras & $1,1 \%$ & $1,6 \%$ & $1,0 \%$ \\
\hline
\end{tabular}

Fuente: elaboración propia.

En el caso de las características de las publicaciones para comunicar politainment, destacan dos tipos de imágenes: mujer común / hombre común y familia / vida privada / amigos. Ambas representan más del 60\% de las publicaciones de ese estilo realizadas tanto por las como por los candidatos. Sin embargo, se registran algunas diferencias: la imagen mujer/hombre común fue un recurso más utilizado por los candidatos que por las candidatas. Si bien ellos emplearon imágenes de sí mismos participando en programas de entretenimiento o infoentretenimiento en menos del $6 \%$ de sus publicaciones, resulta llamativo que ellas no hayan apelado a ese recurso una vez siquiera. En cambio, con referencia a las imágenes con sus familias / vida privada / amigos, las candidatas las utilizaron en $28,9 \%$ de sus publicaciones y los hombres en $23,9 \%$. En el uso del humor hay una diferencia de cuatro puntos en la frecuencia de su mayor empleo por los hombres en comparación con las mujeres (tabla 10).

Tabla 10. Características de las publicaciones de politainment

\begin{tabular}{|l|r|r|r|}
\cline { 2 - 4 } \multicolumn{1}{c|}{} & $\begin{array}{r}\text { Resultados } \\
\text { candidatas }\end{array}$ & $\begin{array}{r}\text { Resultados } \\
\text { candidatos }\end{array}$ & $\begin{array}{r}\text { Resultados } \\
\text { total muestra }\end{array}$ \\
\hline $\begin{array}{l}\text { Mujer/hombre común, humanización } \\
\text { del candidato/a }\end{array}$ & $33,7 \%$ & $37,0 \%$ & $32,8 \%$ \\
\hline $\begin{array}{l}\text { Imágenes participando en programas } \\
\text { de televisión y entretenimiento o } \\
\text { infoentretenimiento }\end{array}$ & --- & $5,9 \%$ & $4,1 \%$ \\
\hline $\begin{array}{l}\text { Con sus familias / vida privada / } \\
\text { amigos personales }\end{array}$ & $28,9 \%$ & $23,9 \%$ & $25,5 \%$ \\
\hline $\begin{array}{l}\text { Las y los candidatos en situaciones } \\
\text { informales con sus equipos de trabajo }\end{array}$ & $15,8 \%$ & $13,0 \%$ & $13,9 \%$ \\
\hline Humor & $6,6 \%$ & $10,7 \%$ & $9,4 \%$ \\
\hline Otras & $15,0 \%$ & $9,5 \%$ & $14,3 \%$ \\
\hline
\end{tabular}

Fuente: elaboración propia. 
Existe una coincidencia en la frecuencia de las características que hombres y mujeres emplean para comunicar habilidades duras de liderazgo. Tal y como se observa en la tabla 11, hay una marcada preferencia por la transmisión de rasgos relacionados con la categoría acción / agencia / ejecutividad / iniciativa.

Tabla 11. Publicaciones y habilidades duras de liderazgo

\begin{tabular}{|l|r|r|r|}
\cline { 2 - 4 } \multicolumn{1}{c|}{} & $\begin{array}{r}\text { Resultados } \\
\text { candidatas }\end{array}$ & $\begin{array}{r}\text { Resultados } \\
\text { candidatos }\end{array}$ & $\begin{array}{c}\text { Resultados } \\
\text { total muestra }\end{array}$ \\
\hline Acción /ejecutividad / iniciativa & $54,3 \%$ & $56,3 \%$ & $55,7 \%$ \\
\hline $\begin{array}{l}\text { Capacidad técnica / competencia } \\
\text { profesional }\end{array}$ & $14,6 \%$ & $11,3 \%$ & $12,3 \%$ \\
\hline $\begin{array}{l}\text { Capacidad de planificación / dirección / } \\
\text { organización estratégica }\end{array}$ & $31,1 \%$ & $32,4 \%$ & $32,0 \%$ \\
\hline
\end{tabular}

Fuente: elaboración propia.

En referencia a la comunicación de habilidades blandas de liderazgo, se registran diferencias en razón del género de los candidatos. Ellos se inclinan más por imágenes que los muestran inspirando entusiasmo $(39,4 \%)$, frente a la elección de estas imágenes por parte de las candidatas (29,4\%). Aunque con menor diferencia, sucede algo semejante con la comunicación de habilidades interpersonales, hacia la que se inclinan más las candidatas que los candidatos. Asimismo, las mujeres optan más por comunicar habilidades de comunalidad / cooperación / colaboración que los hombres (tabla 12).

Tabla 12. Características publicaciones para comunicar habilidades blandas de liderazgo

\begin{tabular}{|l|r|r|r|}
\cline { 2 - 4 } \multicolumn{1}{c|}{} & $\begin{array}{r}\text { Resultados } \\
\text { candidatas }\end{array}$ & $\begin{array}{r}\text { Resultados } \\
\text { candidatos }\end{array}$ & $\begin{array}{r}\text { Resultados } \\
\text { total muestra }\end{array}$ \\
\hline Comunicación / inspirar entusiasmo & $29,4 \%$ & $39,4 \%$ & $36,1 \%$ \\
\hline Flexibilidad / adaptación al cambio & $6,3 \%$ & $3,9 \%$ & $4,7 \%$ \\
\hline $\begin{array}{l}\text { Habilidad para el trabajo en equipo } \\
\text { (mostrarse capaz de interactuar e } \\
\text { integrarse con su equipo de trabajo) }\end{array}$ & $9,3 \%$ & $12,3 \%$ & $11,2 \%$ \\
\hline $\begin{array}{l}\text { Habilidades interpersonales (por } \\
\text { ejemplo, para interactuar, sociabilidad, } \\
\text { empatía con la ciudadanía) }\end{array}$ & $32,9 \%$ & $28,0 \%$ & $29,7 \%$ \\
\hline Cooperación / Colaboración & $22,1 \%$ & $16,4 \%$ & $18,3 \%$ \\
\hline
\end{tabular}

Fuente: elaboración propia.

Las candidatas realizan más publicaciones que sus pares hombres en las que es posible verlas en diversos espacios políticos. Los candidatos publican más imágenes en espacios privados que las mujeres. En cuanto a la vestimenta, los varones se muestran más formales que las candidatas (tabla 13). 
Tabla 13. Otras características de las publicaciones

\begin{tabular}{|c|c|c|c|}
\hline & $\begin{array}{l}\text { Resultados } \\
\text { candidatas }\end{array}$ & $\begin{array}{l}\text { Resultados } \\
\text { candidatos }\end{array}$ & $\begin{array}{c}\text { Resultados } \\
\text { total } \\
\text { muestra }\end{array}$ \\
\hline \multicolumn{4}{|l|}{ Protagonismo de la imagen } \\
\hline Candidata/o & $40,0 \%$ & $44,9 \%$ & $43,2 \%$ \\
\hline Otros políticos & $13,2 \%$ & $5,5 \%$ & $7,8 \%$ \\
\hline Ciudadanía & $24,5 \%$ & $26,6 \%$ & $26,0 \%$ \\
\hline Medios de Comunicación & $5,0 \%$ & $16,1 \%$ & $15,8 \%$ \\
\hline Paisajes & $0,4 \%$ & $1,7 \%$ & $1,4 \%$ \\
\hline Objetos & $2,4 \%$ & $1,4 \%$ & $1,7 \%$ \\
\hline Familia / amigos & $1,1 \%$ & $2,2 \%$ & $1,8 \%$ \\
\hline Colaboradores / equipo de trabajo & $3,0 \%$ & $1,3 \%$ & $1,9 \%$ \\
\hline Otros (no especificar) & $0,4 \%$ & $0,3 \%$ & $0,4 \%$ \\
\hline \multicolumn{4}{|l|}{ Escenario } \\
\hline Espacio político & $44,3 \%$ & $30,7 \%$ & $35,0 \%$ \\
\hline Espacio privado & $21,8 \%$ & $33,7 \%$ & $30,0 \%$ \\
\hline Espacio mediático & $3,6 \%$ & $4,6 \%$ & $4,3 \%$ \\
\hline Espacio público & $30,3 \%$ & $31,0 \%$ & $30,7 \%$ \\
\hline \multicolumn{4}{|l|}{ Vestimenta } \\
\hline Formal & $28,8 \%$ & $41,0 \%$ & $36,5 \%$ \\
\hline Informal & $71,2 \%$ & $59,0 \%$ & $63,5 \%$ \\
\hline \multicolumn{4}{|l|}{ Tipo de apelación dominante } \\
\hline Lógica & $29,2 \%$ & $31,0 \%$ & $30,4 \%$ \\
\hline Emocional positiva & $44,0 \%$ & $49,5 \%$ & $47,7 \%$ \\
\hline Emocional negativa & $1,8 \%$ & $2,2 \%$ & $2,1 \%$ \\
\hline Mixta (Lógica y emocional en partes iguales) & $25,0 \%$ & $17,3 \%$ & $19,8 \%$ \\
\hline
\end{tabular}

Fuente: elaboración propia.

\section{Conclusiones}

Los resultados obtenidos ofrecen algunos elementos para reflexionar acerca del fenómeno del politainment. Esta investigación muestra que, aunque no estuvo ausente, su uso en Instagram no fue predominante y la información de contenido propiamente político fue, en cambio, la preferida en las publicaciones efectuadas tanto por los candidatos hombres como por las mujeres durante la campaña electoral analizada.

Resulta interesante el hecho de que, con frecuencia, una misma publicación combina la información propiamente política con habilidades blandas de liderazgo, lo que facilita que la transmisión de información dura no impida la proyección de una imagen de cercanía emocional de las y los candidatos con la ciudadanía.

En las publicaciones, los candidatos de ambos géneros se inclinaron por elegir exponer las habilidades duras de liderazgo, tales como la capacidad de dirigir, tomar decisiones, planificar y elaborar programas; mientras que los usuarios de Instagram manifiestan su preferencia por las publicaciones en las 
que políticas y políticos comunican habilidades blandas de liderazgo, sobre todo cuando se trata de las publicaciones de las candidatas.

En cuanto a las diferencias por género, resultan menores a las esperadas a priori, cuando se formularon las hipótesis de esta investigación. Las principales diferencias por género se registran en la mayor preferencia de las mujeres por mostrarse en escenarios políticos; así como también en el tipo de vestimenta que se visualiza en las imágenes que fue más formal en el caso de ellos, sobre todo porque en la muestra analizada hay tres candidatos hombres a la presidencia y ninguna mujer. Asimismo, cuando se trata de la comunicación de habilidades blandas, se localizan más imágenes de ellos que proyectan atributos de liderazgo relacionados con la capacidad de inspirar entusiasmo y alentar seguidores; en contraposición a más imágenes de ellas que las mostraban en situaciones de cooperación, colaboración y capacidad de trabajar codo a codo con la comunidad.

\section{Referencias bibliográficas}

BAum, M. A. (2002). Sex, Lies, and War: How Soft News Brings Foreign Policy to the Inattentive Public. American Political Science Review, 96, 91-109. https://doi.org/10.1017/S0003055402004252

BAUM, M. A. (2005). Talking the Vote: Why Presidential Candidates Hit the Talk Show Circuit. American Journal of Political Science, 49, pp. 213-234. https://doi.org/10.1111/j.0092-5853.2005.t01-1-00119.x

BAum, M. A. (2007). Soft News and Foreign Policy: How Expanding the Audience Changes the Policies. Japanese Journal of Political Science, 8 (1). https://doi.org/10.1017/S1468109907002502

BERROCAL, S. (2015). Politainment: el gran espectáculo político televisivo. El Molinillo, 76, pp. 4-9.

Berrocal, S., ABAD. L., Cebrián, E. y Pedreira, E. (2001). La imagen de los partidos políticos en 'El Informal', 'CQC' y 'Las Noticias del Guiñol' en las elecciones legislativas de 2000. ZER. Revista de estudios de comunicación, 11, pp. 167- 185.

Berrocal, S., ABAD. L., CEBrián, E. y PedreiRA, E. (2003). El infoentretenimiento televisivo. Las elecciones legislativas de 2000. En BERROCAL, S. (Coord.), Comunicación Política en Televisión y Nuevos Medios, pp. 282-307. Barcelona: Ariel.

Berrocal, S., CAmpos, E. y Redondo, M. (2012). Comunicación Política en el 'infoentretenimiento' político en YouTube. Estudios del Mensaje Periodístico, 18 (2), pp. 643-659.

https://doi.org/10.5209/rev_ESMP.2012.v18.n2.41037 
BERROCAL, S. y CAMPOS, E. (2012). El 'infoentretenimiento' político en Internet. Un análisis de los videos más vistos en YouTube de José Luis Rodríguez Zapatero y Mariano Rajoy. En BERROCAL, S. y CAMPOS. E (Coord.) $L a$ investigación en Periodismo Político en el entorno de los nuevos medios de comunicación. Madrid: Sociedad Española de Periodística.

BRANTS, K. (1998). Who's Afraid of Infotainment. European Journal of Communication, 13, pp. 315-335.

https://doi.org/10.1177\%2F0267323198013003002

BradY, T. F., KonKLE, T., ALVAREZ, G. A. y Oliva, A. (2008). Visual Long-Term Memory has a Massive Storage Capacity for Object Details. Proceedings of the National Academy of Scienes, Estados Unidos, 108, 14, 325-329. https://doi.org/10.1073/pnas.0803390105

D’ADAMO, O., GARCía BEAUdOUX, V. y KIEVSKY, T. (2015). Comunicación política y redes sociales. Análisis para las campañas y las elecciones legislativas de 2013 en la ciudad de Buenos Aires. Revista Mexicana de Opinión Pública, 19, pp. 107-125.

https://dx.doi.org/10.22201/fcpys.24484911e.2015.19.50206

EKMAN, M. y WidHOLM, A. (2017). Political Communication in an Age of Visual Connectivity: Exploring Instagram Practices among Swedish Politicians. Northern lights: Film \& media studies yearbook, v. 15, n. 1, pp. 15-32. https://doi.org/10.1386/nl.15.1.15_1

GARCíA BEAUDOUX, V. y D'ADAMO, O. (2017). ¿Ideología, imágenes, temas o partidos? Las claves de los anuncios televisivos de las elecciones presidenciales argentinas 2007, 2011 y 2015. En CRESPO, I. y BELINCHÓN, M. (Eds.), ¿Compiten las ideas? La presencia de la ideología en las campañas electorales modernas de Latinoamérica y España, cap. 1, pp. 15-34. Valencia: Tirant Lo Blanch.

García BeAudouX, V. y D’adAMO, O. (2016). Campaña negativa. Análisis de los spots televisivos de siete elecciones presidenciales argentinas (19832011). En Del Rey Morató, J., Campillo, A. B. y Guan, Y. (Eds.), Campañas electorales en América Latina, España y Portugal. Madrid: Fragua.

García BEAUDOUX, V. y D'ADAMO, O. (2016a). Spot y Storytelling. El anuncio televisivo y la narración de historias al servicio de la comunicación política. En LEYVA, O. (Coord.), El spot político en América Latina, pp. 289-314. Guadalajara, México: Universidad de Guadalajara.

GARCíA BEAUDOUX, V. y D'ADAMO, O. (2016b). Spots electorales y publicidad política. En Santiago, J., ORTEGa, M. G. y CarPio, J. A. (Coords.), Consultoría política, Cap. 20, pp. 473-494. Madrid: Ed. Amarante. 
García Beaudoux, V. y D'AdAmo, O. (2013). Propuesta de una matriz de codificación para el análisis de las campañas negativas. Revista OPERA, 13, pp. 7-23.

García Beaudoux, V., D’adamo, O. y Slavinsky, G. (2005). Comunicación Política y Campañas Electorales. Barcelona: Gedisa.

García BeAudouX, V., D’ADAmo, O. y Zubieta, E. (2016). Presidente ideal y comunicación política. Expectativas de los ciudadanos e imágenes proyectadas en los spots de las campañas presidenciales argentinas 2003, 2007 y 2011. Revista Marco, 2, pp. 1-23. https://doi.org/10.15304/marco.2.2842

Garramone, G. M., STEele, M. E. y PinKLEton, B. (1991). The Role of Cognitive Schemata in Determining Candidate characteristics effects. En BIOCCA, F. (Ed.), Television and Political Advertising, 1. Psychological Processes, pp. 311-328. Hillsdale, N.J.: Erlbaum.

Hamilton, J. T. (2004). All the News that's Fit to Sell: How the Market Transforms Information into News. Princeton, NJ: Princeton University Press

IGARTUA, J. J. (2006). Métodos cuantitativos de investigación en comunicación. Barcelona: Bosch.

INSTAGRAM (2017). Instagram's 2017 Year in Review. www.instagrampress.com, Nov. 29.

KRIPPENDORFF K. (1990). Metodología del análisis de contenido. Barcelona: Paidós Comunicación.

LEMISH, D. y TIDHAR, C.E. (1999). Still Marginal: Women in Israel's Television Election Campaign. Sex roles: A Journal of Research, 41, pp. 389-412.

LÓPEZ RABADÁN, P. y DOMÉNECH FABREGAT, H. (2018). Instagram y la espectacularización de las crisis políticas. Las $5 \mathrm{~W}$ de la imagen digital en el proceso independentista de Cataluña. El profesional de la información, 27 (5), pp. 1013-1029. https://doi.org/10.3145/epi.2018.sep.06

LÓPEZ GARCíA, G. (2017). Comunicación política y discursos sobre el poder. El profesional de la información, 26 (4), pp. 573-578.

https://doi.org/10.3145/epi.2017.jul.01

Meyen, M., Thieroff, M. y STEnger, S. (2014). Mass Media Logic and the Mediatization of Politics: A Theoretical Framework Journalism studies, 15 (3), pp. 271- 288. https://doi.org/10.1080/1461670X.2014.889459

MONTAGUT, M. y CARRILLO, N. (2017). Estrategias de espectacularización en las tertulias políticas televisivas. Caso de la cobertura de las elecciones municipales de Barcelona de 2015. El profesional de la información, 26 (4), pp. 621-629. https://doi.org/10.3145/epi.2017.jul.06 
NEUENDORF, K. A. (2002). The content analysis guidebook. Thousand Oaks, CA: Sage.

PATTERSON, T. E. (2000). Doing Well and Doing Good: How Soft News and Critical Journalism are Shrinking the News Audience and Weakening Democracy—and What news Outlets can do About It. Cambridge, MA: Harvard University, John F. Kennedy School of Government.

QUEVEDO REDONDO, R. y PORTALÉS Oliva, M. (2017). Imagen y comunicación política en Instagram. Celebrificación de los candidatos a la presidencia del Gobierno. El profesional de la información, 2 (5), pp. 916-927. https://doi.org/10.3145/epi.2017.sep.13

ReINEMANN, C., STANYER, J., SCHERR, S. y LEGNANTE, G. (2011). Hard and Soft News: A Review of Concepts, Operationalizations and Key Findings. Journalism, 13 (2), pp. 1-19. https://doi.org/10.1177\%2F1464884911427803

RiCHARDSON, K. (2015). Celebrity Politics. En MAZzolENI, G. (Ed.), International Encyclopedia of Political Communication, Vol. I. Chichester, Gran Bretaña: Wiley-Blackwell.

RUIZ-AguilaR, M. A. y AVALOS-PELAYo, R. (2020). Contenido generado por los usuarios, su relación con la personalidad de marca y el valor de marca. index.comunicación, 10(1), 125-147. https://orcid.org/0000-0002-0595-1986

SElVA RUIZ, D. y CARO CASTAÑo, L. (2017). Uso de Instagram como medio de comunicación política por parte de los diputados españoles: la estrategia de humanización en la 'vieja' y la 'nueva' política'. El profesional de la información, 26 (5), pp. 903-915.

https://doi.org/10.3145/epi.2017.sep.12

TOWNER, T. L. y DuLIO, A. D. (2011). An Experiment of Campaign Effects during the YouTube Election. New Media \& Society, 13 (4), pp. 626-644. https://doi.org/10.1177/1461444810377917

TOWNER, T. L. y MuÑOS, C. L. (2017). Picture Perfect? The Role of Instagram in Issue Agenda Setting during the 2016 Presidential Primary Campaign. Social science computer review, 36, (4), pp. 484-499. DOI: https://doi.org/10.1177/0894439317728222

TYRon, CH. (2008). Pop Politics: Online Parody Videos, Intertextuality, and Political Participation. Popular Communication: The International Journal of Media and Culture, 6, (4), pp. 209-213. DOI: https://doi.org/10.1080/15405700802418537

VoGT, S. y MAGNuSSEN, S. (2007). Long Term Memory for 400 Pictures on a Common Theme, Experimental Psychology, 54, 298-503.

https://doi.org/10.1027/1618-3169.54.4.298 
WEARESOCIAL (2018). Special reports. Digital in 2018: World's internet users pass the 4 billion mark. https: / / wearesocial.com/blog/2018/01/global-digital-report-2018

WEARESOCIAL (2020). The World Most Used Social Platforms, January 2020, https: / / www.google.com.ar/amp/s/marketing4ecommerce.net/cual es-redes-sociales-con-mas-usuarios-mundo-2019-top/amp/

WeSt, D. y ORMAN, J. (2002). Celebrity Politics. Englewoods Cliffs: Prentice Hall. WheEler, M. (2013). Celebrity Politics. Londres: Polity. 